\title{
CONFRONTANDO EL DISCURSO DOMINANTE: LAS REMESAS BAJO EL PRISMA DE LA EXPERIENCIA MEXICANA
}

\author{
Confronting the dominant discourse: \\ remittances in the light of the Mexican experience
}

Raúl Delgado Wise*
Selene Gaspar Olvera**

\begin{abstract}
Resumen. El discurso dominante acerca de las remesas como palanca de desarrollo para los países de origen de los migrantes ha resurgido con renovado ímpetu en la agenda internacional, particularmente en el marco del Pacto Global para una Migración Segura, Ordenada y Regular impulsado por la ONU. A partir de datos duros referentes a la experiencia mexicana, nos proponemos contribuir a una necesaria desmitificación del fenómeno, poniendo de relieve que, por encima de sus aportes a la estabilidad macroeconómica y social del país, las remesas se inscriben en una dinámica de intercambio desigual que esencialmente opera a favor del país receptor de migrantes.
\end{abstract}

Palabras clave: remesas; macroeconomía; desarrollo; México; internacional.

\begin{abstract}
The dominant discourse on remittances as a lever of development for migrant's countries of origin has arisen with renewed impetus in the international agenda, particularly within the framework of the Global Compact for Safe, Orderly and Regular Migration propelled by the UN. Based on hard data from the Mexican experience, our propose is to contribute to a necessary demystification of the phenomenon, highlighting that, in addition to its contributions to the country's macroeconomic and social stability, remittances are part of a complex dynamic of unequal exchange which essentially operates in favor of the recipient country.
\end{abstract}

Keywords: remittances; macroeconomic; development; México; international.

Director, Unidad Académica de Estudios del Desarrollo, Universidad Autónoma de Zacatecas. Zacatecas, México.

** Investigadora en la Unidad Académica de Estudios del Desarrollo, Universidad Autónoma de Zacatecas. Zacatecas, México. 


\section{Introducción}

El discurso dominante enarbolado por organismos internacionales como el Banco Mundial y el Banco Interamericano de Desarrollo, tiende a presentar a las remesas como una suerte de río de oro de cuyo torrente se abren anchas avenidas para el desarrollo de los países de origen. Se trata esencialmente de un mito o mantra: la creencia de que las remesas pueden canalizarse hacia inversiones económicas que superen el subdesarrollo. $\mathrm{O}$, dicho de manera más cruda y menos positiva, la idea es que algunos de los trabajadores más explotados del mundo pueden compensar los fracasos de las políticas de desarrollo dominantes. Este discurso ha estado alimentado, por un lado, por el incremento de la migración internacional y particularmente de aquella proveniente de países periféricos. Tómese en cuenta que entre 1990 y 2015, el número de migrantes internacionales se incrementó de 154 a 247 millones, de los cuales alrededor de dos terceras partes provinieron de países periféricos. Por otro lado, en el mismo lapso, las remesas dirigidas a estos últimos países se multiplicaron por 15, al pasar de 29 a 441 mil millones de dólares. Esta última cifra supera en poco más de tres veces el monto global de la ayuda oficial para el desarrollo'.

El propósito de este trabajo es contribuir a una necesaria desmitificación del discurso dominante, a partir de evidencia empírica que permite ubicar en su justa dimensión y desmitificar los alcances y límites de las remesas para el desarrollo los países de origen, tomando como referente el caso de México, a la sazón principal país de emigrantes (a la par de India) y cuarto receptor de remesas (después de India, China y Filipinas) del mundo.

\section{Consideraciones iniciales sobre la dependencia de las remesas}

A lo largo de las últimas tres décadas y media, el objetivo de promover el desarrollo ha sido dejado de lado por los organismos internacionales y los gobiernos en general. Dicha tarea ha sido asignada a un ente abstracto, el mercado, y en este andamiaje guiados por la "mano invisible" de éste, en tanto mecanismo regulador por excelencia según el dogma neoliberal a través de las remesas la migración cumple una doble función: como fuente de divisas para compensar los déficits en la balanza comercial y como vía para generar ingresos familiares ante las fuertes limitaciones de empleo que acusan las economía exportadoras de fuerza de trabajo, como es el caso de la mexicana. Del lado de los países receptores, la migración laboral que es, con mucho, la más significativa viene a cubrir necesidades del mercado laboral no satisfechas internamente, con un aliciente adicional: cubrir esa necesidad con fuerza de trabajo barata y coadyuvando al crecimiento y competitividad internacional de esas economías.

\footnotetext{
1 WORLD BANK. Migration and Remittances Factbook 2016.
} 
Más aún, al abandonar el objetivo del desarrollo -e incluso de cualquier opción de transformación social- los países exportadores de fuerza de trabajo tienden a ocultar su incapacidad para generar los empleos necesarios para su población y desatender las causas profundas de ese déficit: las relaciones de intercambio desigual en las que se hayan atrapados y que, por esta vía, continúa reproduciéndose y profundizándose. En efecto, este proceso se deriva de las dinámicas de desarrollo desigual que caracterizan al capitalismo contemporáneo. A través de estas dinámicas en los países periféricos se engendra una sobreoferta de fuerza de trabajo que obliga a amplios segmentos de la población a emigrar forzosamente y, en contrapartida, en los países centrales se genera una creciente demanda de fuerza de trabajo que no puede ser satisfecha internamente, particularmente en sectores económicos cuya expansión y rentabilidad dependen cada vez más del trabajo de migrantes, como sucede en la agricultura, manufactura, construcción y servicios, incluyendo -sobre todo a partir de la década de 1990- las actividades de innovación². La economía política internacional del trabajo precario se sustenta, por tanto, en una doble y creciente dependencia: de las remesas de parte de los países emisores y de la fuerza de trabajo barata y flexible por parte de los países receptores.

El sistema migratorio México-Estados Unidos no sólo se inscribe en estas tendencias, sino que se erige como un caso paradigmático de la forma perversa en que la migración se integra como pieza clave de los procesos asimétricos de integración económica en el horizonte norte-sur ${ }^{3}$.

De aquí que las remesas familiares funjan como uno de los pilares más conspicuos de la llamada economía de la migración. En esencia, representan un componente o una fracción de un salario precario destinado a cubrir, aun sea en términos limitados, necesidades familiares básicas: alimentación, salud, educación y vivienda en los países y lugares de origen. Y si bien no existe un vínculo directo entre migración y pobreza, resulta incuestionable que las remesas familiares sirven como un paliativo para contrarrestar las condiciones de pobreza y marginación prevalecientes, sin que para ello medie intervención gubernamental alguna.

Desde una óptica macroeconómica, las remesas familiares, cuyo monto en el caso de México ascendió a 27 mil millones de dólares en 2016, operan como una de las más importantes y dinámicas fuentes de divisas, como se detalla en el apartado siguiente. A esto se agregan las remesas colectivas, i.e. los recursos enviados a sus comunidades de origen por las organizaciones de migrantes para obras de beneficio colectivo, las cuales han contribuido, aun sea

2 DELGADO WISE, Raúl, CHÁVEZ ELORZA Mónica Guadalupe, RODRÍGUEZ RAMÍREZ Héctor. La Innovación y la Migración calificada en la Encrucijada: reflexiones a partir de la Experiencia Mexicana. 3 CYPHER, James, DELGADO WISE Raúl. Mexico's Economic Dilemma: The Developmental Failure of Neoliberalism. 
modestamente, a un cierto "desarrollo" social comunitario y fortalecimiento de vínculos transnacionales.

Es importante consigna que en torno a la migración y a las remesas familiares y colectivas han surgido también una serie de empresas que brindan servicios de envío, telecomunicaciones, transporte, turismo, construcción, medios de comunicación y empresas culturales y del entretenimiento, entre otros, las cuales configuran lo se ha dado en llamar -en sentido restringido, en nuestra opinión- industria de la migración ${ }^{4}$.

Visto a través del espejo de las remesas, la imagen que se proyecta acerca de las implicaciones de la migración para los países de origen tiende a dibujar un panorama parcial, distorsionado y unidireccional que ofusca el carácter interdependiente y profundamente asimétrico de la relación entre migración y desarrollo, que se teje bajo la égida neoliberal. Si para los países de origen se genera una dependencia de las remesas, para los países de destino se produce un fenómeno similar: una creciente dependencia de la fuerza de trabajo migrante, aunque con implicaciones muy diferentes y que por lo general son invisibilizadas. Nos referimos a la creciente necesidad que los países de destino tienen de esta fuerza de trabajo y la significativa contribución que ella hace al crecimiento económico de los países receptores. Estimaciones recientes para Estados Unidos develan que, entre 2000 y 2015, el 45.2 por ciento de la demanda laboral de Estados Unidos fue cubierta por trabajadores migrantes y que, en el mismo lapso, el 40.8 por ciento del crecimiento del Producto Interno Bruto (PIB) de dicha economía descansó sobre las espaldas -y el cerebro- de los trabajadores migrantes, con o sin documentos ${ }^{5}$. El aporte de los migrantes mexicanos, la mitad de los cuales reside en condición indocumentada, resulta fundamental en uno y otro caso (14.8 y 14.3 por ciento, respectivamente) y no tiene parangón con el monto de remesas recibidas por el país, por más significativas que éstas sean para la economía familiar y nacional.

\section{Las remesas bajo el prisma de la "estabilidad" macroeconómica}

De acuerdo con datos del Banco Mundial, en 2015 México ocupaba el segundo sitio mundial por su volumen de emigrantes internacionales, con 13.2 millones. En el mismo año India se ubicaba en primer sitio con un volumen de emigrantes ligeramente superior: 13.9 millones. Aun cuando en este rubro México e India se posicionaron casi a la par, al considerar el flujo de remesas la situación se modifica significativamente. Mientras que India ratifica su posicionamiento en el primer sitio mundial, con 72 mil millones de dólares por concepto de remesas, México pasa a la cuarta posición con un monto de

\footnotetext{
4 OROZCO, Manuel. The remittance marketplace: Prices, policy and financial institutions.

5 DELGADO WISE, Raúl, GASPAR OLVERA, Selene. Demystifying irregular migration.
} 
remesas muy inferior: 27 mil millones de dólares ${ }^{6}$. Más allá de las múltiples razones que explican tal descenso (crisis financiera en Estados Unidos, política de criminalización del gobierno de ese país hacia los mexicanos y centroamericanos, etc.), lo cierto es que el flujo de remesas ha seguido un curso ascendente entre 1995 y 2016 (aunque marcado por una fase de relativo estancamiento asociado a la crisis financiera en Estados Unidos), al pasar de 3.6 a 27 mil millones de dólares.

No cabe duda de que las remesas desempeñan un papel fundamental como fuente de divisas para los países exportadores de fuerza el cual resulta crucial para el sostenimiento de su "estabilidad" macroeconómica, aun sea en términos precarios. En el caso de México la importancia de tal soporte se evidencia, meridianamente, al considerar que el ingreso por remesas correspondió en 2016 a 142.9 por ciento de las exportaciones petroleras, 136.9 por ciento de las divisas por turismo, 100.2 por ciento de la inversión extranjera directa y 7.6 por ciento de las exportaciones no petroleras (Gráfica 1$)^{7}$.

\section{Gráfica 1. Importancia de las remesas en México, 1995-2016}

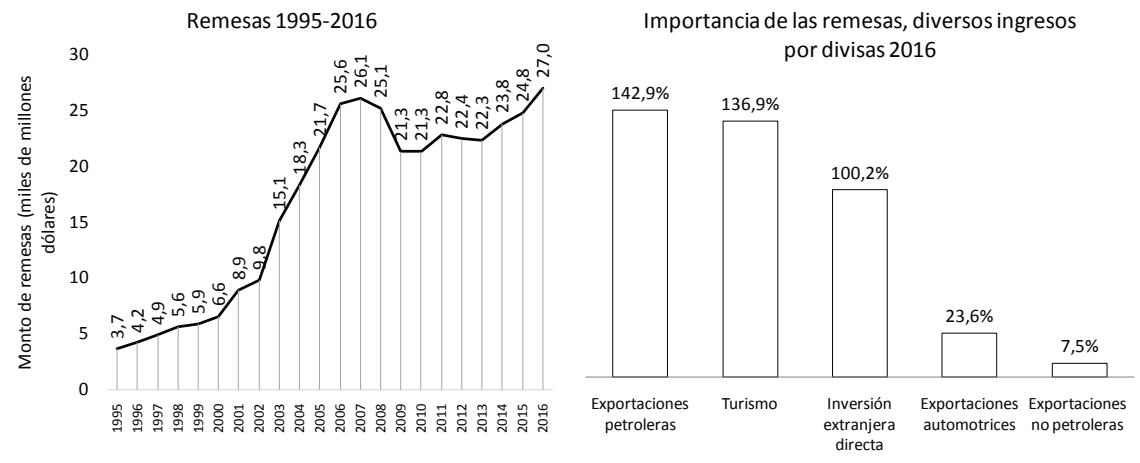

Fuente: Elaboración propia con base en datos del Banco de México, 1995-2016.

La importancia de las remesas para los países exportadores de fuerza de trabajo varía en función de las dimensiones de la economía y el grado de "desarrollo" relativo que detenten, en el marco de su condición periférica. Así por ejemplo, el peso de las remesas respecto del PIB en México (2.7 por ciento) tiende a ser menor que en otros países de la región y en especial de aquellos

\footnotetext{
WORLD BANK, op. cit.

Cabe advertir que existe también un flujo de remesas en sentido opuesto, de los países de origen a los de destino, destinado a apoyar a los migrantes en el país de destino en periodos críticos de su estancia, sobre todo para quienes detentan una situación de irregularidad en su estatus migratorio. En 2016 el monto de remesas enviadas desde México a Estados Unidos fue de 308 millones de dólares (GARCÍA ZAMORA, Rodolfo, GASPAR OLVERA Selene. La inclusión de la migración en la revisión del TLC elemento impostergable en la relación binacional).
} 
que configuran el triángulo norte de Centroamérica: Guatemala, Honduras y El Salvador (gráfica 2).

\section{Gráfica 2. Importancia de las remesas en el mundo, 2015}
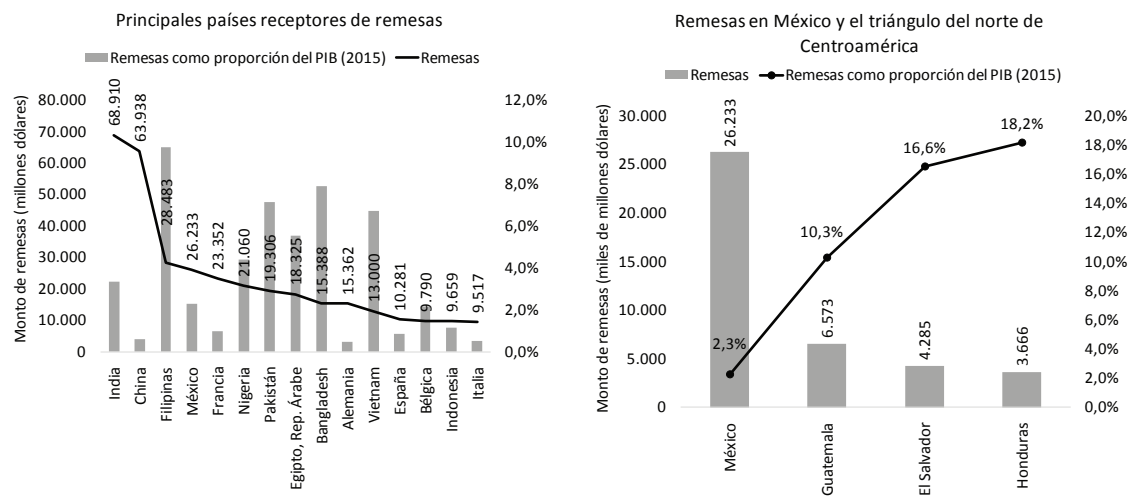

Fuente: Elaboración propia con base en datos del Banco de México, 1995-2016.

Y si bien resulta incuestionable el soporte de las remesas para la "estabilidad" macroeconómica de México, no es menos cierto que difícilmente debe valorárseles como un ingreso benéfico per se para el desarrollo del país. Se trata, ante todo, de un producto y un resultado de la modalidad de integración asimétrica y subordinada de la economía mexicana a la estadounidense, donde las remesas constituyen un eslabón básico de la lógica perversa del modelo exportador de fuerza de trabajo implantado en el país ${ }^{8}$. En este sentido, las remesas, lejos de enmarcarse en un juego de suma cero donde el país emisor y receptor se benefician equitativamente, son reflejo de las dinámicas de desarrollo desigual en las que se encuentra atrapado el país, donde los costos en sentido amplio de las remesas (más allá de los costos de transferencia de las mismas) tienden a ser muy superiores a sus beneficios. Sobre este punto, por lo demás significativo para contrarrestar el discurso dominante, ahondaremos en el apartado final de este trabajo.

\section{Las remesas como fuente de subsistencia familiar}

En virtud de la limitada capacidad para generar empleo y la precariedad del mismo que prevalece en el territorio nacional, las remesas familiares han sido concebidas como una suerte de welfare para millones de familias mexicana9 . En 2008 había 1.7 millones de hogares receptores de remesas en México (6.1 por ciento del total de hogares). Como consecuencia de la crisis económica desencadenada en Estados Unidos este monto, según estimaciones

\footnotetext{
8 CYPHER, DELGADO WISE, op. cit.

9 GOLDRING, Luin. El Estado mexicano y las organizaciones transmigrantes: ¿reconfigurando la nación y las relaciones entre Estado y sociedad civil?
} 
propias basadas en datos de la ENIGH, se redujo a 1.6 millones en 2016 (5 por ciento del total de hogares). Por encima de su innegable importancia para la subsistencia de las familias que reciben remesas y el limitado impacto multiplicador que éstas tienen por la vía del consumo, sería absurdo suponer que semejante ingreso, diseminado entre millones de hogares, pudiera convertirse en una palanca para el desarrollo del país.

El patrón de gasto de las remesas familiares en México tiende a ser similar, de acuerdo con lo consignado en diversos estudios en la materia. Su uso principal está dirigido a la satisfacción de necesidades básicas, incluyendo salud y educación, mientras que un remanente se destina al ahorro o pequeñas inversiones en vivienda, terrenos, ganado y establecimientos comerciales. Además los usos referidos, es pertinente advertir que existen las llamadas remesas especiales destinadas a ahorro o inversión, como puede ser la compra de una casa, maquinaria agrícola, participación en proyectos de inversión o en programas gubernamentales. De acuerdo con la Encuesta Nacional de Inclusión Financiera (INIF, 2015), el principal destino de las remesas familiares es para gastos de comida, personales y pago de servicios (59.3 por ciento), le sigue su uso para atender enfermedades, emergencia o imprevistos (25.4 por ciento), educación de los hijos (7.1 por ciento) y la compra, reparación, ampliación o remodelación del hogar (4.9 por ciento). Tan solo el 2.5 por ciento se destina a inversión en un negocio y el 2.1 por ciento para comprar algún bien o activo (animales, terrenos, autos, etc.). Otros gastos ocupan el 10.2 por ciento (Cuadro 1).

Cuadro 1. Uso de las remesas en México, 2015

\begin{tabular}{lccc}
\hline & Total & Urbano & Rural \\
\hline Gastos de comida, personales o pago de servicios & 53.3 & 53.1 & 66.8 \\
Atender una enfermedad, emergencia o imprevisto & 25.4 & 27.3 & 23.2 \\
Comprar, reparar, ampliar o remodelar una casa & 4.9 & 4.1 & 5.9 \\
Pagar deudas & 4.4 & 5.0 & 3.8 \\
Educación de los hijos & 2.7 & 8.3 & 5.7 \\
Invertir en el negocio & 2.5 & 1.4 & 3.8 \\
Comprar algún bien o activo (animales, terrenos, autos, etc.) & 2.1 & 2.3 & 1.8 \\
Otro & 10.2 & 10.9 & 9.3 \\
\hline
\end{tabular}

La suma de los porcentajes es igual o mayor a 100 por ciento, dado que el informante podía mencionar más de una opción. Fuente: Elaboración propia con base en INEGI. Encuesta Nacional de Inclusión Financiera (INIF) 2015.

A nivel familiar, las remesas han sido asociadas a la reducción de la pobreza; sin embargo, la evidencia disponible muestra que se trata de una opción insuficiente e insegura para tal propósito. Más del 80 por ciento de las remesas son utilizadas para la satisfacción de necesidades básicas, lo que evidencia no solo su importancia para los hogares que las reciben, sino también 
el riesgo que tienen de caer en una situación de insustentabilidad económica ante la condición inestable e insegura del empleo en Estados Unidos, agravada por la crisis por la que atraviesa la economía de ese país ${ }^{10}$.

\section{Alcances y limitaciones de las remesas colectivas}

Como lo consignamos antes, las remesas colectivas aluden a recursos recaudados por las organizaciones de migrantes que son canalizados a obras sociales y públicas en los lugares de origen. Por el entramado organizacional, el tejido de relaciones y la necesaria negociación con los distintos niveles de gobierno (federal, estatal y municipal) involucrados, en este tipo de remesas están implicadas relaciones transnacionales acordes a la estirpe de las organizaciones de migrantes. A través de ellas es posible:

- la realización de obras a nivel local para atender necesidades de infraestructura social;

- el estrechamiento de vínculos sociales y culturales entre los migrantes y sus comunidades de origen, $y$

- la apertura de un canal institucional para la rendición de cuentas.

A nivel general, las remesas colectivas se refieren a iniciativas de clubes y asociaciones o federaciones de migrantes con el gobierno mexicano en sus tres niveles. Se trata de iniciativas de las organizaciones de migrantes que con el paso del tiempo desembocaron en el Programa Tres por Uno ${ }^{11}$. En 2014, el programa Tres por Uno apoyó 2,901 proyectos en 611 municipios mexicanos. Entre los apoyos otorgados por este programa, destaca, como se aprecia en el cuadro 2, el mejoramiento de vivienda y la realización de proyectos productivos, esencialmente en pequeña escala.

\section{Cuadro 2. Apoyos otorgados por el Programa 3×1, 2014}

\begin{tabular}{lrr}
\hline & Numero beneficiarias(os) & $\begin{array}{r}\text { Importe de los apoyos } \\
\text { Peso mexicano (MXN) }\end{array}$ \\
\hline Total general & $\mathbf{2 , 9 0 1}$ & $\mathbf{2 3 , 3 7 8 , 8 8 3}$ \\
Apoyo por concepto de beca & 895 & 349,999 \\
Mejoramiento de vivienda & 263 & $9,011,902$ \\
Metros cuadrados de piso firme & 175 & 300,001 \\
Techo de losa de concreto $m^{2}$ & 118 & 750,000 \\
Proyecto productivo & 1,450 & $12,966,981$ \\
\hline
\end{tabular}

Fuente: Elaboración propia con base en Secretaría de Desarrollo Social.

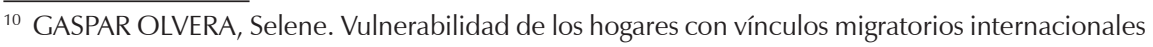
en México.

${ }^{11}$ GARCÍA ZAMORA Rodolfo. Migración, remesas y desarrollo: Los retos de las organizaciones migrantes mexicanas en Estados Unidos. 
Las obras realizadas bajo este programa abarcan desde la pavimentación de calles y rehabilitación de iglesias hasta obras de infraestructura productiva como carreteras y presas. Debido a restricciones presupuestales principalmente del gobierno federal, muchos proyectos e iniciativas de las organizaciones de migrantes no pudieron ser ejecutadas en el marco del programa. Se trata esencialmente de una modalidad de transnacionalismo "desde abajo" que, entre otras cosas, ha posibilitado:

1. fortalecer la organización transnacional de los migrantes;

2. abrir canales de negociación de las organizaciones de migrantes y sus comunidades de origen con los tres niveles del gobierno mexicano;

3. financiar la construcción de miles de proyectos de infraestructura básica;

4. favorecer un proceso de aprendizaje social transnacional, y

5. impulsar una cultura de la transparencia y rendición de cuentas ${ }^{12}$.

Por encima de los innegables logros alcanzados por el Programa Tres por Uno, el cual ha sido tildado como ejemplo de "buenas prácticas" a nivel internacional, lo cierto es que se trata apenas de un aliciente de alcances limitados frente a los enormes desafíos que plantea la problemática de desarrollo enfrentada por los países exportadores de fuerza de trabajo. En este sentido, las remesas colectivas no pueden ni deben ser concebidas como sustituto de las políticas públicas para el desarrollo.

\section{Impacto de las remesas en el desarrollo humano y la pobreza}

Es común suponer que la pobreza induce migración, y que ésta a su vez es fuente de remesas. Si tal postulado fuese cierto, las entidades y municipios con menores niveles de ingresos per cápita, educación y salud tendrían un gran número de migrantes internacionales y, por lo tanto, recibirían una significativa cantidad de remesas. Empero, la distribución geográfica de las remesas en el país revela una realidad muy distinta.

En términos absolutos, según datos del Banco de México, los estados de Michoacán, Estado de México, Guerrero, Guanajuato, Puebla, Oaxaca, Ciudad de México e Hidalgo concentraron el 55.4 por ciento de las remesas en 2016. Cada uno de ellos recibió remesas en un monto superior a $\$ 1,000$ millones de dólares. En 2010, de esos ocho estados, cinco de ellos (Michoacán, Guerrero, Puebla, Oaxaca e Hidalgo) pertenecen al grupo de los diez estados con menores niveles de desarrollo humano del país. Los otros cuatro estados receptores de remesas, México, Guanajuato y la Ciudad de México pertenecen al grupo de las diez economías estatales más grandes del país. A pesar de su elevado índice de desarrollo humano, estos estados concentran 20.5 por ciento de las remesas recibidas en 2016. En contraste, cuatro de los diez estados con

\footnotetext{
12 Ibidem.
} 
bajo índice de desarrollo humano (Chiapas, Zacatecas, Tabasco y Tlaxcala) captan solamente 6.8 por ciento de las remesas nacionales (mapa 1 y cuadro 3). Al analizar la distribución geográfica de las remesas en términos relativos, la situación anterior se sostiene. Todo esto revela que no existe una relación mecánica entre remesas y desarrollo humano a escala estatal, donde es difícil diferenciar el impacto específico de las remesas.

\section{Mapa 1. Tasa de emigración 2014-2015 y monto de remesas 2016 por entidad federativa}

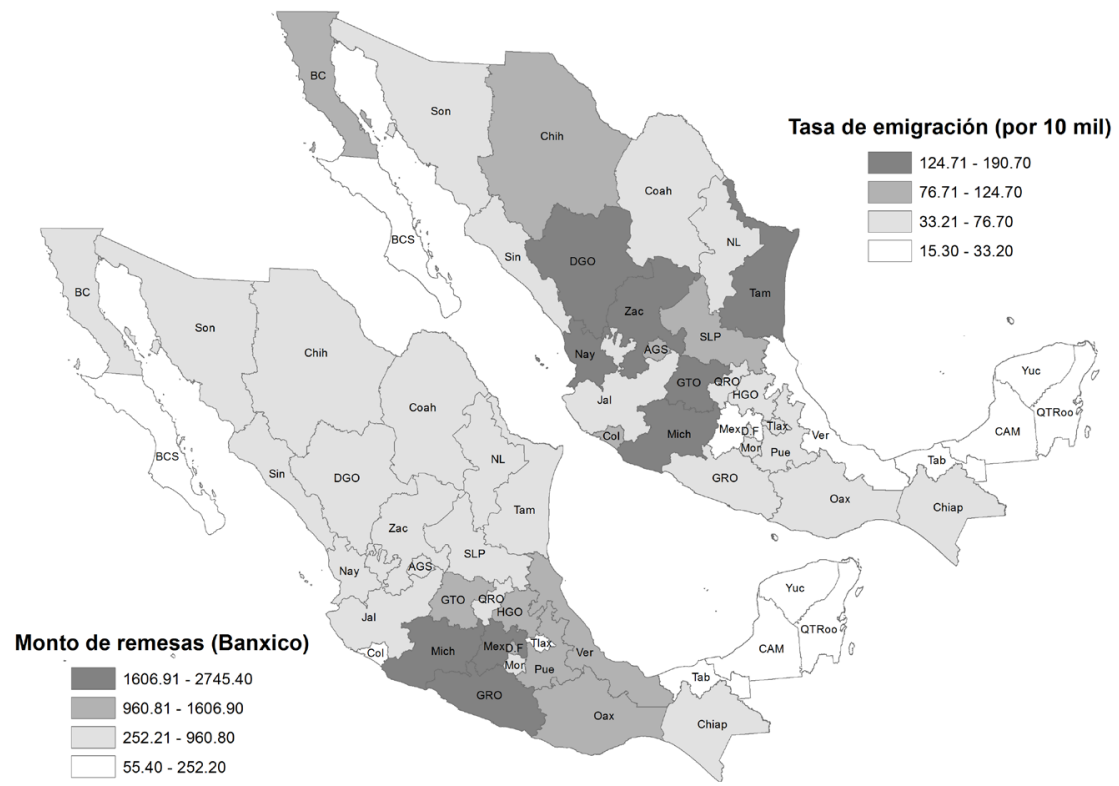

Fuente: Elaboración propia con dados de INEGI (Tasa de emigración ENOE). Remesas (Banxico).

De acuerdo con estimaciones derivadas de la base de datos de CONEVAL para la medición de la pobreza, los hogares receptores de remesas pasaron de 1.2 millones en 2014 a casi 1.6 millones en 2016; de estos últimos 674 mil se clasifican en pobreza por ingreso (42.3\%). Mientras el número de hogares receptores de remesas se incrementó en 35.5\% entre 2014 y 2016, el número de hogares receptores de remesas en situación de pobreza se incrementó en $19.8 \%$. Una manera aproximada de ver el impacto de las remesas en los hogares receptores es bajo el supuesto de que éstas se dejaran de percibir. En este caso, los resultados revelan que sin su concurso, existe un elevado riesgo de que los hogares se sumerjan en condiciones de pobreza y/o se incremente su situación de vulnerabilidad. Más aún, los resultados del nivel de pobreza muestran que sin el ingreso por remesas internacionales el número de hogares pobres en 2016 se hubiese elevado en 178 mil (ver Cuadro 3). 


\section{Cuadro 3. Hogares perceptores de remesas por condición de pobreza, 2014 y 2016}

\begin{tabular}{lrrr}
\hline \multicolumn{1}{l}{ No pobres } & Pobres & Total \\
\hline $\begin{array}{l}\text { Medición de la pobreza considerando el ingreso por remesas } \\
\text { Hogares }\end{array}$ & & \\
2014 & 613,197 & 562,492 & $1,175,689$ \\
\hline 2016 & 919,735 & 673,715 & $1,593,450$ \\
\hline Crecimiento absoluto & 306,538 & 111,223 & 417,761 \\
Crecimiento porcentual & 50.0 & 19.8 & 35.5 \\
\hline Población (2016) & $3,130,432$ & $2,782,778$ & $5,913,210$ \\
\hline
\end{tabular}

Medición de la pobreza sin considerar el ingreso por remesas

Hogares

\begin{tabular}{lrrr}
2014 & 398,599 & 777,090 & $1,175,689$ \\
\hline 2016 & 637,820 & 955,630 & $1,593,450$ \\
\hline Crecimiento absoluto & 239,221 & 178,540 & 417,761 \\
Crecimiento porcentual & 60.0 & 23.0 & 35.5 \\
\hline Población (2016) & $2,267,275$ & $3,645,935$ & $5,913,210$ \\
\hline
\end{tabular}

Fuente: Estimación propia con base en las bases de datos de CONEVAL para la medición de la pobreza 2014 y 2016.

De acuerdo con datos de la Encuesta Nacional de Ingreso y Gasto de los Hogares (ENIGH) 2016 el número de hogares receptores de remesas se incrementó en 418 mil hogares, al pasar de 1.2 millones en 2014 a 1.6 millones en 2016. Más allá de este significativo aumento, es pertinente recordar que en 2008 el número de hogares receptores de remesas era de 1.7 millones y de 1.2 millones en 2012. Ello implicó una caída en el número de hogares receptores de $29.4 \%$ entre 2008 y 2012, atribuible principalmente a la crisis desencadenada en Estados Unidos y la consecuente caída en el flujo migratorio hacia ese país. Esta situación muestra que existen diferencias importantes al analizar los datos a nivel estatal, donde como se muestra la gráfica 3, en únicamente cuatro entidades se registró una caída y en el resto, aunque en proporciones disímiles, hubo un cierto incremento. 
Gráfica 3. Porcentaje de hogares perceptores de remesas 2014 y 2016

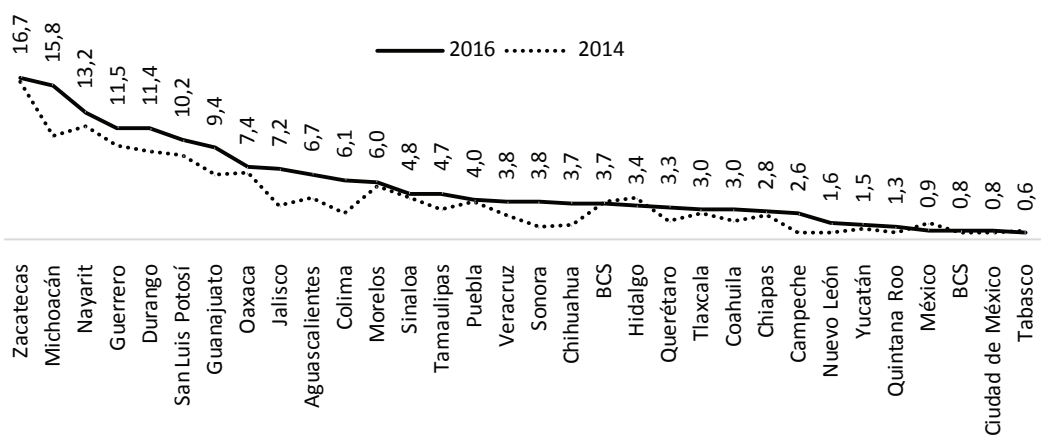

Fuente: Estimación propia con base en las bases de datos de CONEVAL para la medición de la pobreza 2014 y 2016.

Más aún, al enfocarnos en el fenómeno de la pobreza, es posible apreciar en $2014^{13}$ que, para un número importante de hogares por entidad federativa, las remesas no operan como avenida para reducir la pobreza y sí como un factor que indica el riesgo latente, en caso de que se dejasen de recibir, de situar a los dependientes del hogar en situación de mayor vulnerabilidad económica. Llama la atención, en este sentido, el alto porcentaje de hogares receptores de remesas que se ubican en situación de pobreza, particularmente en los estados de Puebla, Chiapas, Guerrero y Michoacán, donde más de seis de cada diez hogares con remesas son pobres. Con todo, los datos en general sobre la proporción de hogares en pobreza son alarmantes (gráfica 4).

\section{Gráfica 4. Porcentaje de hogares perceptores de remesas en pobreza 2014}

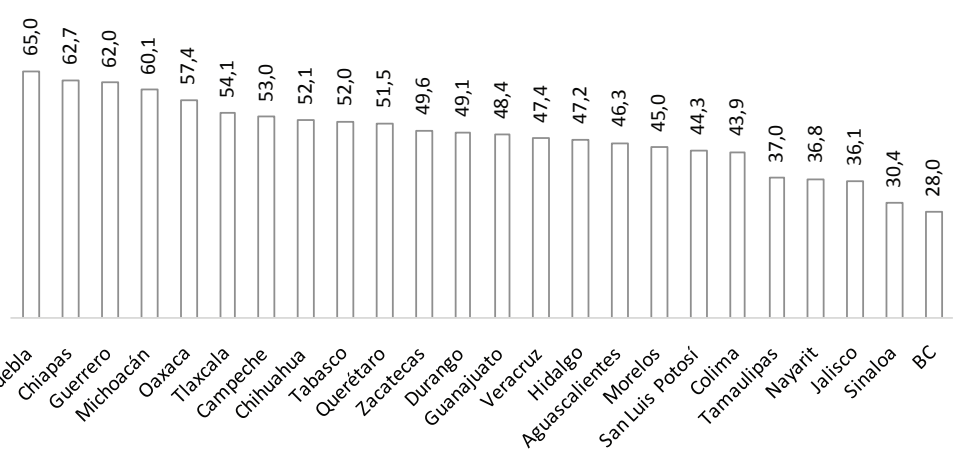

Fuente: Estimación propia con base en las bases de datos de CONEVAL para la medición de la pobreza 2014.

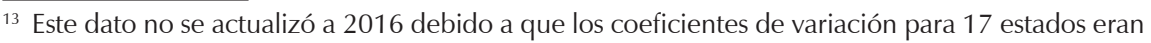
superiores a 15\%. Para las estimaciones de 2014 se obtuvieron para BCS, Estados de México, Quintana Roo, Coahuila, Sonora y Yucatán coeficiente de variación entre 16 y 22\%. Para la Ciudad de México CV: 33.5\% y Nuevo León con CV: 40.2\%. 
$\mathrm{Al}$ analizar el peso relativo que tiene el monto de remesas captadas por los hogares sobre el ingreso corriente, se observa que en los hogares en situación de pobreza las remesas tienen un mayor peso, particularmente en los estados de mayor emigración y menor índice de desarrollo humano. Cabe destacar que aún en los hogares no pobres las remesas tienen un peso relativo importante respecto del ingreso corriente del hogar (Mapa 2). Y si bien no existe un vínculo directo entre migración y pobreza, resulta evidente que las remesas familiares operan como un paliativo para aminorar las condiciones de pobreza y marginación, sin que en ello medie la intervención gubernamental. Además, debe considerarse que la emigración internacional implica un costo -además de un riesgo creciente- que se ha venido acrecentando con el reforzamiento de las medidas de control fronterizo; costo que los miembros de los hogares más pobres difícilmente pueden sufragar. De aquí que no se deban plantear vinculaciones mecánicas entre migración y pobreza. En el mejor de los casos, es posible señalar que la migración y las remesas contribuyen a atenuar la pobreza y la marginación en las comunidades de origen, sin que por ello puedan ser concebidas como una solución de fondo para su erradicación o combate.

\section{Mapa 2. Hogares que reciben remesas según condición de probreza. Peso relativo del monto de remesas respecto del ingreso corriente del hogar 2014}

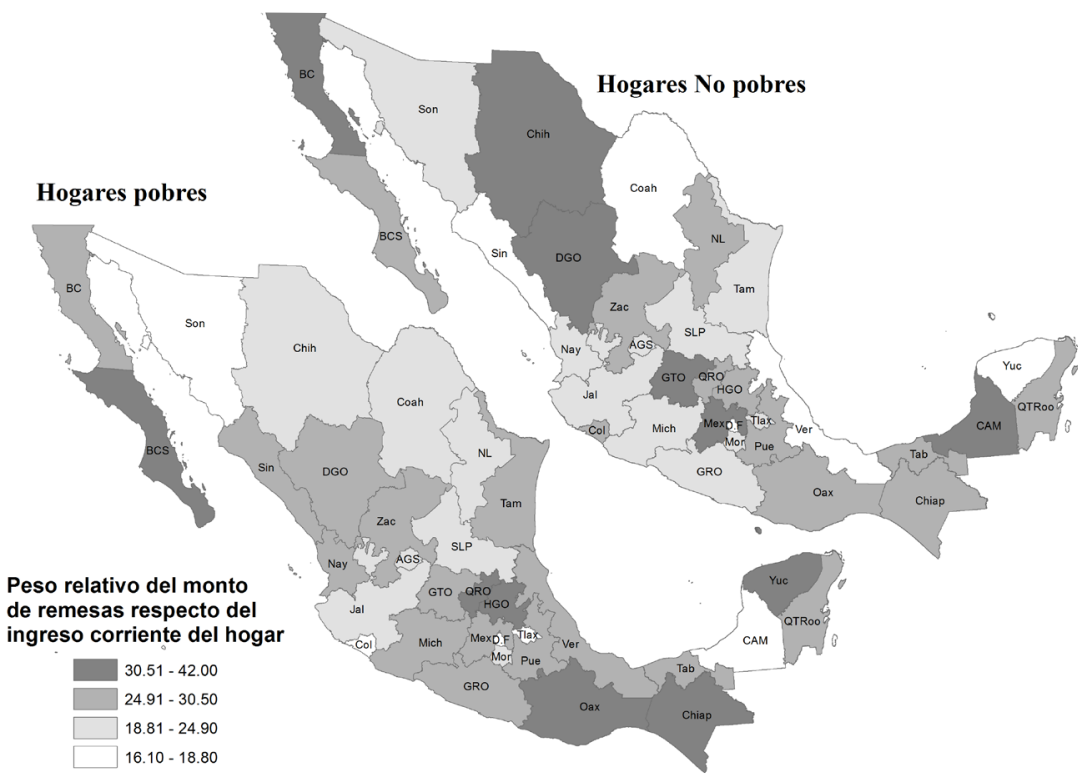

Fuente: Estimación propia con base en INEGI. Encuesta de Ingreso y Gasto de los Hogares (ENIGH) 2014. Base CONEVAL. 
De lo hasta aquí analizado, es posible apreciar que:

1. Dada la relativa disminución de la migración mexicana hacia los Estados Unidos es previsible que el flujo de remesas hacia México tienda desacelerarse e incluso disminuir -como de hecho ha venido sucediendo- y afectar, con ello, la estabilidad macroeconómica del país.

2. Puesto que el destino principal de las remesas es el consumo familiar y en mucho menor medida la inversión productiva, resulta falaz suponer que puedan convertirse en un fondo social de inversión capaz de detonar el desarrollo local o regional. Más aún, ante las limitaciones del sistema financiero mexicano para proveer de recursos crediticios a las localidades y regiones de origen de los migrantes, el esquema de microfinanzas asociado a la captación de remesas dista mucho de fungir como alternativa de desarrollo a esos niveles ${ }^{14}$.

3. Puesto que las remesas han demostrado sus limitaciones para elevar el ingreso y contrarrestar la riqueza de los hogares que las reciben, difícilmente pueden suplir las responsabilidades gubernamentales en materia de combate a la pobreza y promoción del desarrollo social.

4. La creciente conformación de hogares con vínculos migratorios internacionales y la relación que guardan con factores de exclusión y dependencia económica -remesas y programas gubernamentales los coloca en una situación de desventaja y vulnerabilidad social, en comparación con los hogares sin migrantes ${ }^{15}$.

\section{La industria de la migración: impactos y limitaciones}

La llamada industria de la migración ha sido considerada como una cadena de actividades económicas que se derivan directa e indirectamente de las migraciones internacionales en los países de origen y destino. Además del impacto directo sobre las familias, la migración es creadora de una amplia fábrica de actividades con impactos multiplicadores sobre las economías locales y regionales, sin negar que tiene también consecuencias negativas en estos ámbitos, como es el caso del despoblamiento, el abandono de actividades productivas asociado a él y la dependencia cada vez más crítica de las remesas ${ }^{16}$.

Es evidente, por tanto, que en torno a la economía de la migración concurren tanto ganadores como perdedores. Por un lado, a través de la demanda de bienes y servicios asociados a las remesas han surgido empresas que se benefician de sus impactos multiplicadores a nivel local y regional. Por otro lado, la transferencia de remesas entraña un negocio muy lucrativo para empresas como Western Union y Money Gramm, así como una amplia gama

${ }^{14}$ CORTINA, Jerónimo, DE LA GARZA, Rodolfo, OCHOA-REZA, Enrique. Remesas: límites al optimismo.

15 GASPAR OLVERA, op. cit.

16 PAPADIMETRIOU, Demetriou. Reflections on the Relationship between Migration and Development. 
de instituciones bancarias privadas involucradas en el negocio. A pesar de algunos esfuerzos e iniciativas de organismos internacionales como el Banco Interamericano de Desarrollo para disminuir el costo de las transferencias y la formación de un sector microfinanciero vinculado al envío, recepción y uso local de remesas, persisten aún -como se aprecia en el cuadro 4-costos elevados de envío de remesas de Estados Unidos a México y Centroamérica.

Cuadro 4. Costo promedio del envío de remesas 2010 y 2017

\begin{tabular}{|c|c|c|c|c|c|c|c|}
\hline & México & $\begin{array}{l}\text { Costa } \\
\text { Rica* }\end{array}$ & $\begin{array}{c}\text { El } \\
\text { Salvador }\end{array}$ & Guatemala & Honduras & Nicaragua & Panamá \\
\hline \multicolumn{8}{|l|}{2017} \\
\hline Cuota & 4.77 & 7.88 & 7.95 & 7.13 & 8.20 & 9.84 & 9.90 \\
\hline $\begin{array}{l}\text { Margen de cambio } \\
\text { (por ciento) }\end{array}$ & 2.72 & 1.44 & 0 & 1.21 & 0 & 0 & 0 \\
\hline $\begin{array}{l}\text { Costo total } \\
\text { (por ciento) }\end{array}$ & 5.11 & 5.38 & 3.98 & 4.77 & 4.10 & 4.92 & 4.95 \\
\hline Costo total (USD) & 10.20 & 10.76 & 7.95 & 9.55 & 8.20 & 9.85 & 9.90 \\
\hline \multicolumn{8}{|l|}{2010} \\
\hline Cuota & 10.99 & 13.55 & 9.13 & 9.80 & 8.58 & 11.78 & 14.33 \\
\hline $\begin{array}{l}\text { Margen de cambio } \\
\text { (por ciento) }\end{array}$ & 1.93 & 1.53 & 0 & 1.41 & 0.12 & 0 & 0 \\
\hline $\begin{array}{l}\text { Costo total } \\
\text { (por ciento) }\end{array}$ & 7.42 & 8.30 & 4.57 & 6.31 & 4.41 & 5.89 & 7.17 \\
\hline Costo total (USD) & 14.85 & 16.61 & 9.13 & 12.61 & 8.82 & 11.79 & 14.33 \\
\hline
\end{tabular}

* Datos corresponde a 2015.

Fuente: Elaboración propia datos del Banco Mundial (<https://remittanceprices.worldbank.org/>).

Más aún, como parte de la llamada industria de la migración: a) se han expandido y dinamizado los servicios de transporte aéreo y terrestre de migrantes, incluyendo actividades asociadas al turismo paisano e incluso al traslado de cadáveres; b) se ha dado un importante impulso a los medios de telecomunicación como el Internet y el sistema de telecomunicaciones, y c) se ha ampliado y diversificado el consumo de productos y bienes culturales originarios de los países y localidades de origen de los migrantes, configurando lo que conoce como mercado nostálgico o paisano.

Sin embrago, ante el relativamente escaso desarrollo de la comunidad empresarial migrante, las actividades de la llamada industria de la migración tienden a ser aprovechadas por las grandes corporaciones multinacionales, principalmente de los países receptores, y en menor medida de los emisores. Tal es el caso de las tiendas Coppel, Elektra, Famsa (36.8 por ciento), empresas como Western Union, Money Gramm, etc (26.6 por ciento) y sucursales bancarias (13.7 por ciento), estos tres medios agrupan el 77.1 por ciento de las remesas que ingresan a México (véase cuadro 5). 
Cuadro 5. Empresas que participan en el negocio de las remesas

\begin{tabular}{lccc}
\hline & Total & Urbano & Rural \\
\hline Tiendas (Coppel, Elektra, Famsa) & 36.8 & 36.8 & 36.7 \\
Remesadora (Western Union, Money Gram, etc.) & 26.6 & 32.3 & 19.9 \\
En una sucursal bancaria (orden de pago o cheque) & 13.7 & 9.3 & 18.9 \\
Cuenta Bancaria & 9.5 & 12.8 & 5.5 \\
Familiar o conocido(a) & 6.3 & 5.3 & 7.5 \\
Telecomm o Sepomex & 6.3 & 2.1 & 10.3 \\
Supermercado & 2.1 & 4.3 & 0.6 \\
Transferencia electrónica & 1.8 & 3.6 & 1.0 \\
Otro & 4.7 & 4.1 & 6.8 \\
\hline
\end{tabular}

Fuente. Elaboración propia con base en INEGI, Encuesta Nacional de Inclusión Financiera (INIF, 2015).

En un sentido más amplio, la vida transnacional ha dado lugar a una amplia gama de actividades económicas en los lugares de origen y destino inscritas en la lógica y dinámica global del desarrollo económico de los países que encabezan los procesos de globalización neoliberal, como es el caso de Estados Unidos. Lo importante a destacar es que más allá de la modificación de los patrones de consumo tanto en los lugares de origen como de destino, la llamada industria de la migración se inserta en el engranaje que reproduce las asimetrías y mantiene el statu quo entre los países de origen y destino de los migrantes ${ }^{17}$.

\section{¿Quién subsidia a quién?: estimación en sentido amplio del costo de las remesas}

Nuestro análisis de la relación entre remesas y desarrollo quedaría incompleto si no consideramos una dimensión crítica de las remesas, que por lo general ha sido ofuscada en la literatura disponible en la materia. Nos referimos al costo en sentido amplio -i.e. más allá de los costos de transferencia o envío- de las remesas para los países de origen de los migrantes. Al respecto, resulta importante advertir que además del beneficio económico que implican las remesas para el país de origen, las familias y las empresas relacionadas con la llamada industria de la migración, la migración y la posibilidad de recibir remesas implica un costo primigenio para el país de origen. Los migrantes no crecen por generación espontánea ni adquieren la educación que tienen al momento en que emigran sin costo alguno. En efecto, la inserción laboral de los migrantes mexicanos en Estados Unidos implica una transferencia de recursos derivados de los costos de reproducción educativa y social de la fuerza

${ }_{17}$ GUARNIZO, Luis Eduardo. The economics of transnational living. 
de trabajo. Estos costos fueron cubiertos en México a través de programas de educación, salud y asistencia social. La migración laboral representa, en este sentido, un ahorro en términos de la formación de fuerza de trabajo para Estados Unidos y un costo para México.

Partiendo de las consideraciones anteriores, al considerar el nivel de escolaridad de los migrantes mexicanos que arribaron por vez primera a Estados Unidos y el costo implícito en la formación de la fuerza de trabajo tomando como referente los costos correspondientes a los diferentes niveles de educación pública en México, es posible sostener que entre 1994 y $2008^{18}$, el país transfirió 83 mil millones de dólares (a precios de 2008) a su vecino del norte. Más aún, haciendo esta misma estimación bajo el supuesto alterno de que los niveles de escolaridad que los migrantes mexicanos trajeron consigo a Estados Unidos se hubieran alcanzado en las escuelas públicas de ese país ${ }^{19}$, el costo educativo habría sido de 613 mil millones de dólares (a precios constantes de 2008) en el mismo periodo.

Si además del costo educativo, consideramos que la migración implica una transferencia de recursos invertidos en la reproducción social de la fuerza de trabajo antes de que emigre. Estos recursos incluyen una diversidad de rubros como el bienestar público, programas sociales y gastos familiares (entre ellos una porción notable de las remesas, que contribuyen a la formación de la nueva fuerza laboral emigrante). Se trata de costos que de suyo difíciles de medir, pero que constituyen la base socioeconómica para la formación de la fuerza de trabajo que migra allende las fronteras.

Si calculamos el costo de reproducción social a partir de un indicador simple y en múltiples sentidos conservador: la canasta básica estimada por el Consejo Nacional para la Evaluación de la Política de Desarrollo Social, en tanto una expresión del costo de vida, la transferencia de México a Estados Unidos entre 1994 y 2008 por este concepto asciende a 257 mil millones de dólares (a precios de 2008).

Al sumar los costos educativos a los de reproducción social, es posible concluir que el costo total transferido por México a Estados Unidos fue de al menos 340 mil millones de dólares, lo que implica 1.8 veces del total de remesas recibidas en el periodo de referencia. Más aún, esta cifra de suyo reveladora del costo en sentido amplio -y no reconocido- de las remesas, se elevaría significativamente al considerar los costos de reproducción social y

\footnotetext{
${ }^{18}$ Escogimos este año y no 2015 para estas estimaciones a fin de evitar la distorsión en la estimación que pudiera derivarse del efecto de la crisis financiera desencadenada en 2007-2008 y sus secuelas.

${ }^{19}$ En este caso nuestra estimación se basó en información del National Center for Education y U.S. Department of Education en combinación con datos de la Current Population Survey referentes al nivel de escolaridad de los inmigrantes mexicanos a su llegada a Estados Unidos.
} 
educativos en Estados Unidos, es decir, el costo de oportunidad que representa la fuerza de trabajo migrante para ese país.

Al considerar el costo en sentido amplio de las remesas, en los términos en los que lo hemos discutido en este apartado, resulta evidente que la sociedad mexicana subsidia a la economía estadounidense a través de la migración laboral y no al revés como lo postula el discurso dominante sobre la relación entre remesas y desarrollo. Se trata, por consiguiente, de una modalidad de intercambio desigual entre el país de origen y destino que no suele ser reconocida y que, de considerársele, cambiaría radicalmente las percepciones que comúnmente se tienen del fenómeno migratorio.

\section{A manera de conclusión}

Nos encontramos ante un escenario internacional hegemonizado por la ideología neoliberal, que denuesta la intervención estatal a favor del mito de "libre mercado", escatimando el hecho de que nos encontramos en una etapa del capitalismo mundial donde las grandes corporaciones multinacionales controlan el grueso del mercado mundial. Bajo estas circunstancias, la gestión del desarrollo tiende a ser relegada por los organismos internacionales y los gobiernos nacionales, particularmente en el caso de los países periféricos exportadores de fuerza de trabajo. Para estos últimos la migración laboral es visualizada como una fuente insoslayable de divisas y una vía para suplementar las limitaciones nacionales de empleo. En el caso particular de México, el proceso de integración económica con Estados Unidos bajo el andamiaje del Tratado de Libre Comercio de América del Norte encierra una dinámica de desarrollo desigual (sustentada en la emergencia de nuevas modalidades de intercambio desigual) que, por un lado, contribuyen al crecimiento de la economía y la satisfacción de las necesidades del mercado laboral estadounidenses y, por el otro, al desmantelamiento de las cadenas productivas y el estrechamiento y precarización del mercado laboral formal y el creciente mercado informal en México.

Bajo estas circunstancias, las remesas familiares figuran como un pilar fundamental para el sostenimiento de la alicaída economía mexicana tanto a nivel micro (principalmente como fuente de subsistencia familiar), como a nivel macro (en tanto fuente insoslayable de divisas para el sostenimiento de la economía nacional). Figuran, por tanto, como una pieza clave del engranaje neoliberal del país.

Por su parte, las remesas colectivas han posibilitado, en un sentido muy restringido, la realización de obras sociales comunitarias y aunque son un termómetro de la vitalidad (en descenso) del llamado "transnacionalismo desde abajo", lo cierto es que representan también, sin que ello sea parte de 
la agenda de los migrantes, un elemento que favorece la estabilidad social del país sin tocar las fibras más sensibles del modelo exportador de fuerza de trabajo imperante.

El fenómeno migratorio ha dado lugar al surgimiento de una serie de empresas que brindan servicios de envío de remesas, telecomunicaciones, transporte, turismo, construcción, medios de comunicación y empresas culturales y del entretenimiento, entre otros, que configuran la llamada industria de la migración comandada por grandes corporaciones multinacionales, principalmente de origen estadounidenses.

Más allá del espejismo o mantra de las remesas, que implica concebirlas -como lo sigue haciendo el Banco Mundial y sus epígonos- como una palanca de desarrollo para los países de origen, lo cierto es que, como se demostró en el apartado anterior, lejos de representar un subsidio norte-sur, significan exactamente lo opuesto: una transferencia de los costos educativos y de reproducción social de la fuerza de trabajo migrante del país de origen al país de destino. Se trata, en este sentido, de una modalidad de intercambio desigual.

A esto último habría que agregar otro dato que por lo general ha sido invisibilizado en el debate internacional en materia de migración y desarrollo. Nos referimos a la contribución directa que los migrantes laborales y en particular los mexicanos hacen a la economía de Estados Unidos. Al respecto, se estima que el aporte de los migrantes mexicanos al Producto Interno Bruto (PIB) de los Estados Unidos creció en 136.7 por ciento entre 1997 y 2016, al pasar de 346 a 819 mil millones de dólares. Más aún, a pesar de la contracción y estancamiento relativo de la economía estadounidense en el periodo 2008-2016, los mexicanos incrementaron su contribución al PIB en 14.3 por ciento y pagaron en impuestos al fisco 26.2 mil millones de dólares; cifra esta última que equivale al monto total de remesas recibidas por México en $2016^{20}$. Se trata, sin duda, de un dato que pone de relieve los verdaderos alcances de la relación entre remesas y desarrollo, así como la distribución desigual o asimétrica de sus resultados. Queda claro, por tanto, el carácter restringido y mistificador del discurso dominante en torno a las remesas y el significado real de la relación dialéctica que se teje entre migración y desarrollo en el horizonte norte-sur.

\section{Referencias}

BANCO DE MÉXICO. Remesas familiares. Recuperado de <www.banxico.org.mx> . BANCO IBEROAMERICANO DE DESARROLLO (BID). Recuperado de < http:// www.iadb.org/es/banco-interamericano-de-desarrollo,2837.html >.

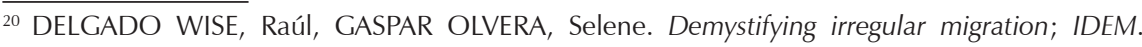
¿Quién subsidia a quién? Contribuciones de los migrantes mexicanos a la economía de EE.UU. 
CASTLES, Stephen; DELGADO WISE, Raúl. Migración y Desarrollo: perspectivas desde el sur. México: Miguel Ángel Porrúa, 2007.

CONEVAL, Consejo Nacional de Evaluación de la Política de Desarrollo Social. Recuperado de <http://www.coneval.org.mx/>.

CORTINA, Jerónimo; DE LA GARZA, Rodolfo; OCHOA-REZA, Enrique. Remesas: límites al optimismo. Foreign Affairs en español, v. 5, n. 3, 2005, p. 27-36.

CYPHER, James; DELGADO WISE Raúl. Mexico's Economic Dilemma: The Developmental Failure of Neoliberalism. New York: Rowman \& Littlefield, 2011. DEPARTAMENTO DE ASUNTOS ECONÓMICOS Y SOCIALES. World Population Prospects. Revision 2006. Recuperado de < http://www.un.org/esa/population/ publications/wpp2006/WPP2006_Highlights_rev.pdf $>$.

DELGADO WISE, Raúl; GASPAR OLVERA, Selene. Demystifying irregular migration. 2017. Recuperado de < https://www.researchgate.net/publication/318216823 Demystifying_Irregular_Migration_A_critical_perspective $>$.

DELGADO WISE, Raúl; CHÁVEZ ELORZA, Mónica Guadalupe; RODRÍGUEZ RAMÍREZ Héctor. La Innovación y la Migración calificada en la Encrucijada: reflexiones a partir de la Experiencia Mexicana. REMHU, Revista Interdisciplinar da Mobilidade Humana, v. 24, n. 47, 2016, p. 24-47.

DELGADO WISE, Raúl; GASPAR OLVERA, Selene. ¿Quién subsidia a quién? Contribuciones de los migrantes mexicanos a la economía de EE.UU. Observatorio del Desarrollo, n. 2, UAED, UAZ, 2012, p. 4-9.

GARCÍA ZAMORA, Rodolfo; GASPAR OLVERA, Selene. La inclusión de la migración en la revisión del TLC elemento impostergable en la relación binacional. Brújula ciudadana, Nueva Época, n. 89, Junio 2017, p. 45-54.

GARCÍA ZAMORA, Rodolfo. Migración, remesas y desarrollo: Los retos de las organizaciones migrantes mexicanas en Estados Unidos. Doctorado en Estudios del Desarrollo UAZ, 2005.

GASPAR OLVERA, Selene. Vulnerabilidad de los hogares con vínculos migratorios internacionales en México. Revista Diarios de Terruño, n. 3, 2017, p. 13-39. 2017.

GOLDRING, Luin. El Estado mexicano y las organizaciones transmigrantes: ¿reconfigurando la nación y las relaciones entre Estado y sociedad civil? In MUMMERT, Gail (comp.). Fronteras fragmentadas. Michoacán: El Colegio de Michoacán/Centro de Investigación y Desarrollo del Estado de Michoacán (CIDEM), 1999.

GUARNIZO, Luis Eduardo. The economics of transnational living. International migration review, v. 37, n. 3, 2003, p. 666-699.

INEE. Indicadores del Sistema Educativos Nacional. Panorama Educativo de México. $<$ http://www.oei.es/historico/pdf2/panorama-educativo-mexico-2008.pdf>.

INEGI. INIF 2015. Encuesta Nacional de Inclusión Financera. Recuperado de: <http://www.cnbv.gob.mx/Inclusión/Documents/Encuesta\%20Nacional\%20 de\%20IF/ENIF\%202015.pdf>. 
INEGI. ENIGH. Encuesta Nacional de Ingreso y Gasto de los Hogares. <www.inegi. org. $m x>$.

INSTITUTO NACIONAL PARA LA EVALUACIÓN DE LA EDUCACIÓN (INEE). $<$ http://www.inee.edu.mx/>.

OROZCO, Manuel. The remittance marketplace: Prices, policy and financial institutions. Washington, DC: Pew Hispanic Center, 2004.

OROZCO, Manuel. Globalization and migration: The impact of family remittances in Latin America. Latin American politics and society, v. 44, n. 2, 2002, p. 41-66.

PAPADIMETRIOU, Demetriou. Reflections on the Relationship between Migration and Development. Seminar on International Migration and Development in North and Central America, México, 1998.

SCHIANTARELLI, Fabio. Global economic prospects 2006: economic implications of remittances and migration. The World Bank, 2005.

SISTEMA DE INFORMACIÓN SOBRE MIGRACIÓN Y DESARROLLO (SIMDE).

U.S. CENSUS BUREAU, CURRENT POPULATION SURVEY (CPS) MARCH SUPPLEMENT.

WORLDBANK.Migrationand RemittancesFactbook2016. Thirdedition. Washington, D.C.: World Bank, 2016. Recuperado de: <https://siteresources.worldbank.org/ INTPROSPECTS/Resources/334934-1199807908806/4549025-1450455807487/ Factbookpart1.pdf $>$.

Recibido para publicación en 16.10.2017

Aceptado para publicación en 23.01.2018 Received for publication in in October 16 ${ }^{\text {th }}, 2017$ Accepted for publication in January 23 ${ }^{\text {th }}, 2018$

ISSN impresso 1980-8585

ISSN eletrônico 2237-9843

http://dx.doi.org/10.1590/1980-85852503880005214 